\title{
Comparison of Surface Modification of CR-39 Polymer Film Using RF and DC Glow Discharges Plasma
}

\author{
Mohamed Hassouba ${ }^{1,2}$, Nagia Dawood ${ }^{1}$ \\ ${ }^{1}$ Physics Department, Faculty of Sciences, Taibah University, Medina, KSA \\ ${ }^{2}$ Physics Department, Faculty of Sciences, Benha University, Benha, Egypt \\ Email:ndawood@taibahu.edu.sa,hassouba@yahoo.com
}

How to cite this paper: Hassouba, M. and Dawood, N. (2017) Comparison of Surface Modification of CR-39 Polymer Film Using $\mathrm{RF}$ and DC Glow Discharges Plasma. Journal of Modern Physics, 8, 2021-2033. https://doi.org/10.4236/jmp.2017.812122

Received: October 12, 2017

Accepted: November 25, 2017

Published: November 28, 2017

Copyright (c) 2017 by authors and Scientific Research Publishing Inc. This work is licensed under the Creative Commons Attribution International License (CC BY 4.0).

http://creativecommons.org/licenses/by/4.0/

\section{(c) (i) Open Access}

\begin{abstract}
Surfaces of optical elements are deposited by antireflection coatings (ARCs) to decrease the reflection of light. Surface needs treatment before depositing the ARC one of treatment processes by plasma for adhesion improvement and surface hardening. A comparison of RF and DC glow discharges treated CR-39 polymer films gives insight into the mechanism of these surface processes. The surface properties of the plasma-treated samples are examined by microscopy techniques include contact angle measurements, scanning electron microscopy (SEM), atomic force microscopy (AFM), infrared (IR) spectroscopy and refractive index measurements. Results show that the plasma treatment modifies the polymer surface in both composition and morphology. It is found that the surface wettability is enhanced after plasma treatment. It is found that, RF plasma is more effective than DC plasma in CR-39 surface modification, as it implants more oxygen atoms into the surface and makes the contact angle declining to a lower level.
\end{abstract}

\section{Keywords}

Surface Modification by Plasma, RF Discharge, DC Discharge, CR-39 Polymer Film

\section{Introduction}

Surface modification by gas discharge plasmas plays a crucial role in the microelectronics industry [1] [2] [3] [4].

Exposure of polymers to suitable plasmas can cause chemical and physical changes to their surface or near-surface layers. These changes produce more reactive surfaces and affect wetting properties, cross-linking and molecular 
weight. Surfaces can thus be engineered to achieve the necessary properties, such as wettability [5], adhesion, barrier protection, material selectivity and even biocompatibility [6]. Therefore, plasma surface modification can induce a specific surface chemistry without altering the bulk properties of the material [7] [8].

Glow discharge plasmas produce the appropriate electron number density and active-species flux for nearly all plasma surface treatment applications. The usual objective of such plasma processing is to increase the surface energy of the material, which leads to better printing, bonding, wettability and wickability [9].

The most widely used materials for plastic spectacle lenses are CR-39 and polycarbonate (PC), as well as polymethyl methacrylate (PMMA) in some cases. These plastic materials are not as brittle as glass and thus do not break easily, but they are relatively soft and can be easily scratched [10].

Srivatsa et al. 2008 [11] developed fabricated deposition system, for depositing fairly hard, durable and efficient antireflection coatings on polycarbonate substrates. The process involves making the normally hydrophobic surface of the polycarbonate substrate (CR-39) wettable, followed by the deposition of a surface-hardening layer of carbonyl silica, and finally the deposition of a four-layer antireflection coating comprising alternating layers of silicon dioxide and titanium dioxide, of specified thicknesses. The spectral transmittance characteristics of the deposited composite antireflection coating, which is fairly hard and durable, compare quite well with the calculated spectral characteristics of the optimum designed coating.

The aim of the present work is to compare between the plasma treatment of CR-39 polymer films using two different plasma sources, namely RF and DC glow discharges. Contact angle, scanning electron microscope (SEM), atomic force microscopy (ATM), infrared (IR) spectroscopy, and refractive index measurements were used to investigate and characterize surface treated of the used polymer.

\section{Experimental Setup}

The discharge plasma was formed in two parallel plate configuration of stainless-steel 304 electrodes with a diameter of $5 \mathrm{~cm}$ and spacing $6 \mathrm{~cm}$, housed in a cylindrical stainless-steel vacuum chamber of $25 \mathrm{~cm}$ in diameter and height. The side and back of the two electrodes were covered with ceramic casing to prevent additional discharge. The lower electrode was powered by RF source $(13.56 \mathrm{MHz}$ and $0-200 \mathrm{~W}$ power), type ENI model OEM-6, through a matching box, while the upper electrode as well as the stainless-steel discharge chamber were grounded. Also, the discharge chamber was operated using 2000 VDC power supply, whereas the current was varied between 5 - $20 \mathrm{~mA}$. The chamber was pumped down by a vacuum system to base pressure of $10^{-4}$ torr.

During all measurements, continues flow of a gas through the discharge chamber was maintained. High purity argon gas was used as working gas and was fed to the chamber through a needle valve. By using the needle valve one can 
control of the gas amount introduce to the plasma system. The pressure of the working gas was varied between $1-10$ torr and measured using a digital vacuum gauge (VAP 5).

Figure 1 shows a schematic drawing of the experimental setup.

Surface characterization of CR-39 polymer was conducted using UV-Vis-Nir scanning spectrophotometer from Shimadzu-Japan model 3101 PC, scanning electron microscopy SEM (JSEM 7400F, Joel, Japan), atomic force microscopy AFM (CP-11 SPM, Veeco, USA) and contact angle measurements were done using a goniometer (Rame' Hart, USA).

\section{Material}

Ally glycol carbonate CR-39 polymer films were obtained from PPG industries, Inc., Italy.

CR-39, specifically poly-diethylene glycol is allyl carbonate, is a plastic polymer commonly used in the manufacture of spectacle lenses. CR-39 is a trademarked product of PPG Industries, USA; originally developed by Columbia Chemical Co. (CR stands for Columbia Resin). It is harder, stronger and more brittle than most other polymer materials, because of the formation of cross-links between the various constituent functional groups. CR-39 is transparent in the visible spectrum and almost completely opaque in the UV range. It has the highest abrasion/scratch resistance of any uncoated optical plastic. CR-39 is about half the weight of glass and its refractive index (1.450) is only slightly lower than that of crown glass, making it an advantageous material for spectacle lenses.

Because of the presence of the two allyl functional groups, the monomer can

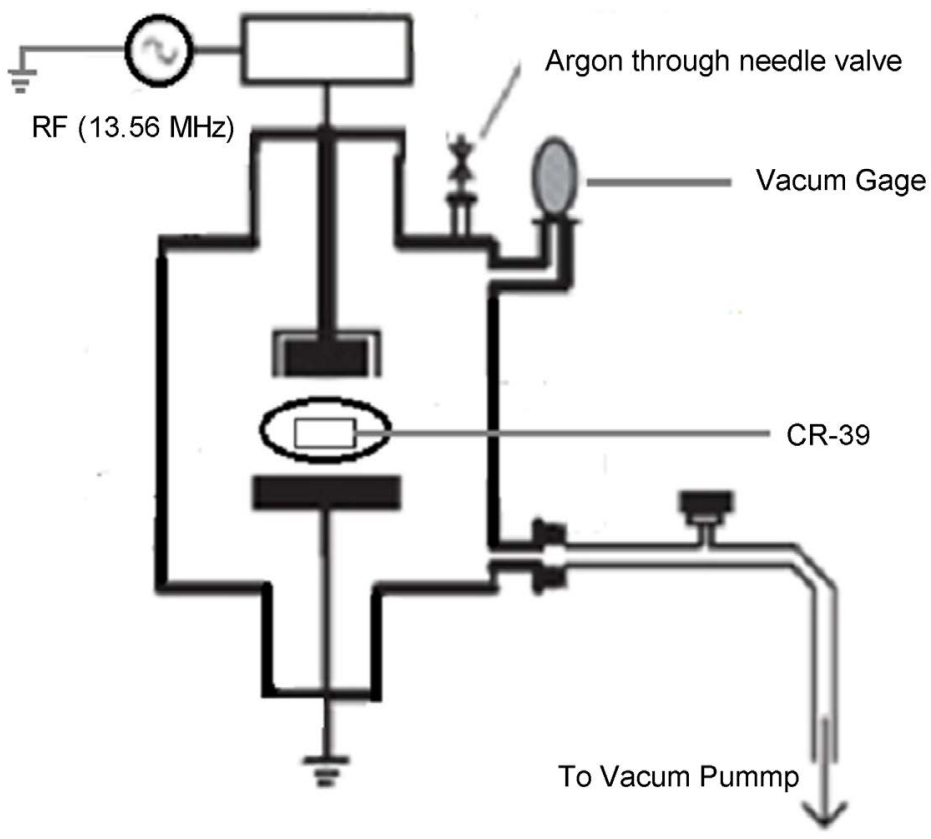

Figure 1. Schematic diagram of experimental apparatus. 
not only polymerize but also cross-link-which results in a thermoset plastic and not a thermoplastic. Thermosetting polymers which form random three dimensional cross-linked structures are characterized by being infusible and insoluble in all solvents. A sample of thermosetting material can be considered to be a single molecule, since covalent bonds link every portion of the material with every other.

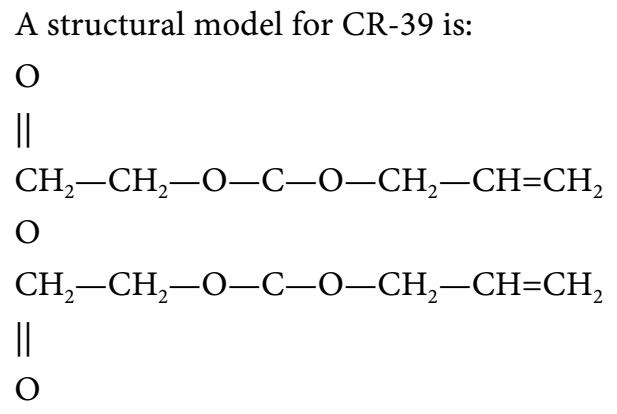

\section{Results and Discussion}

It is reported that [12], higher RF plasma powers often destroy the monomers and therefore moderate RF power would be ideal. So, in the present work, (50 - 150 W) RF power was used for considering surface polymer modifications.

It's well known that argon plasma produce UV photons which enable to optimize the cross-linking process and improving the ageing of the polymer [13] [14] [15]. By breaking the allylic molecules, numerous radicals are formed which react together to create new covalent bonds between the macromolecules [16]. The radicals created on the surface can cause cross-linking and/or react with species generated from the plasma phase [17]. Also, the interaction between metastable states of argon gas plasma and the polymer surface certainly increases the surface energy.

\subsection{Contact Angle Measurements}

Surface wetting is a phenomenon that makes a film adheres well to the surface. Due to its passive nature, the wettability of the plastic surface is very low. To make the surface wettable, it is necessary to increase the surface energy by creating dangling bonds. This can be done by exposing the plastic surface to high energy UV radiation [18], but it is difficult to tailor the required energy. Another approach where the required energy can be applied to the surface is the plasma technique, in which the surface is bombarded with energetic ions like $\mathrm{Ar}^{+}$ions. In this technique, energy of $\mathrm{Ar}^{+}$ions can be tightly controlled by the exciting voltage/power, or with the external bias [19]. With the applied energy, various bonds on the polymer surface will break, and then they are ready to form bonds with ad atoms [11].

The wettability of a surface is measured by the contact angle of a water drop on the surface. Contact angle measurements were performed on the plasma modified surfaces to evaluate the effect of plasma cross-linking on surface hy- 
drophilicity. Several runs have been carried out to optimize the practical process parameters to get good surface wettability, which has been checked visually by applying a drop of water on the surface.

Figure 2 presents the contact angle measured on the treated CR-39 films as a function of plasma treatment time, for both plasma sources. The untreatedCR-39 has a hydrophobic surface exhibiting a contact angle of $110.5^{\circ}$. After the surface modification, the contact angle decreased to $60.8^{\circ}$ for RF plasma and to $65.5^{\circ}$ for DC plasma. It is seen that, an apparent decrease in contact angle takes place with the plasma treatment time, which suggests that an increase in wettability of the CR-39 surface is induced by the RF and DC glow discharges. When the treatment time exceeds $15 \mathrm{~min}$, the measured contact angles reach nearly a saturation state, suggesting that the physical and chemical changes induced by the plasma are also in saturation state when the plasma dose (plasma treatment time) is in excess of some critical values. The decrease in contact angle is indicative of increasing total surface energy due to an enhanced polar component of surface energy [20].

On the other hand, the wettability of the treated polymer film by RF plasma is greater than that of DC plasma; this may due to the energy of the species generated from RF plasma was greater than that of DC plasma. The accelerated ions under the RF and/or DC fields are collide and ionize more gaseous species which strikes the polymer on its surface and causes etching and chain scission to increase the energy of the surface as indicated by lowering of contact angle. The broken bonds on the surface may get functionalized by oxygen and carbon containing radicals. There is also damage of the chains in the subsurface region by more energetic ionic species. There is a limit to damage on the surface, which is probed by the contact angle, which attains a minimum. It may be inferred that as

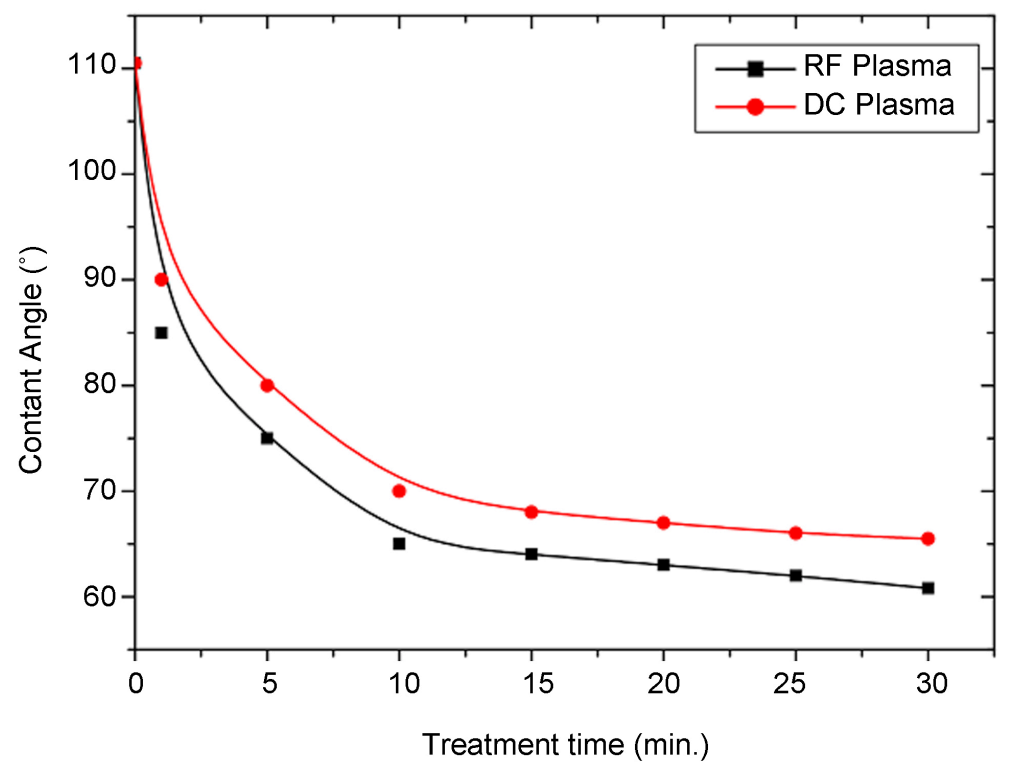

Figure 2. Variation of contact angle measured on the treated CR-39 films as a function of plasma treatment time. 
the functionalization of chains takes place, a competing mechanism of chain scission and cross-linking also takes place during exposure to glow discharge plasma [21]. This cross-linking makes the surface rigid thus preventing the movements of various functional groups on the surface. The change in the wetting is generally associated with incorporation of various functional groups at the polymer surface as well as cross-linking and chain scission [22].

Also, the use of glow discharge plasma enables to disregard the degradation process in relation to the functionalization process. Thus the increase of the polymer wettability is mainly due to the formation of polar functions which are of great interest to a better understanding of the treatment aging. Polar functions orient themselves toward the polymer bulk and may interact with another one to form hydrogen bonds, which establish physical linkages within the surface and its stabilization [23].

\subsection{SEM Measurements}

Figure 3(a) shows SEM of an untreated sample of CR-39 film. A few grains are embedded in the surface of the sample. Figures 3(b)-(d) shows SEM of CR-39 film made after direct exposure, for 1, 5 and $10 \mathrm{~min}$, to $5 \mathrm{~mA} \mathrm{DC}$ plasma and at 1 torr gas pressure. Also, Figures 4(b)-(d) shows SEM of CR-39 film made after direct exposure, for 1,5 and $10 \mathrm{~min}$, to 100 watt power RF plasma and at 1 torr gas pressure. There is no indication in the field of view of the SEM pictures of pitting or melt. The film gently scrapped from the surfaces was found to be
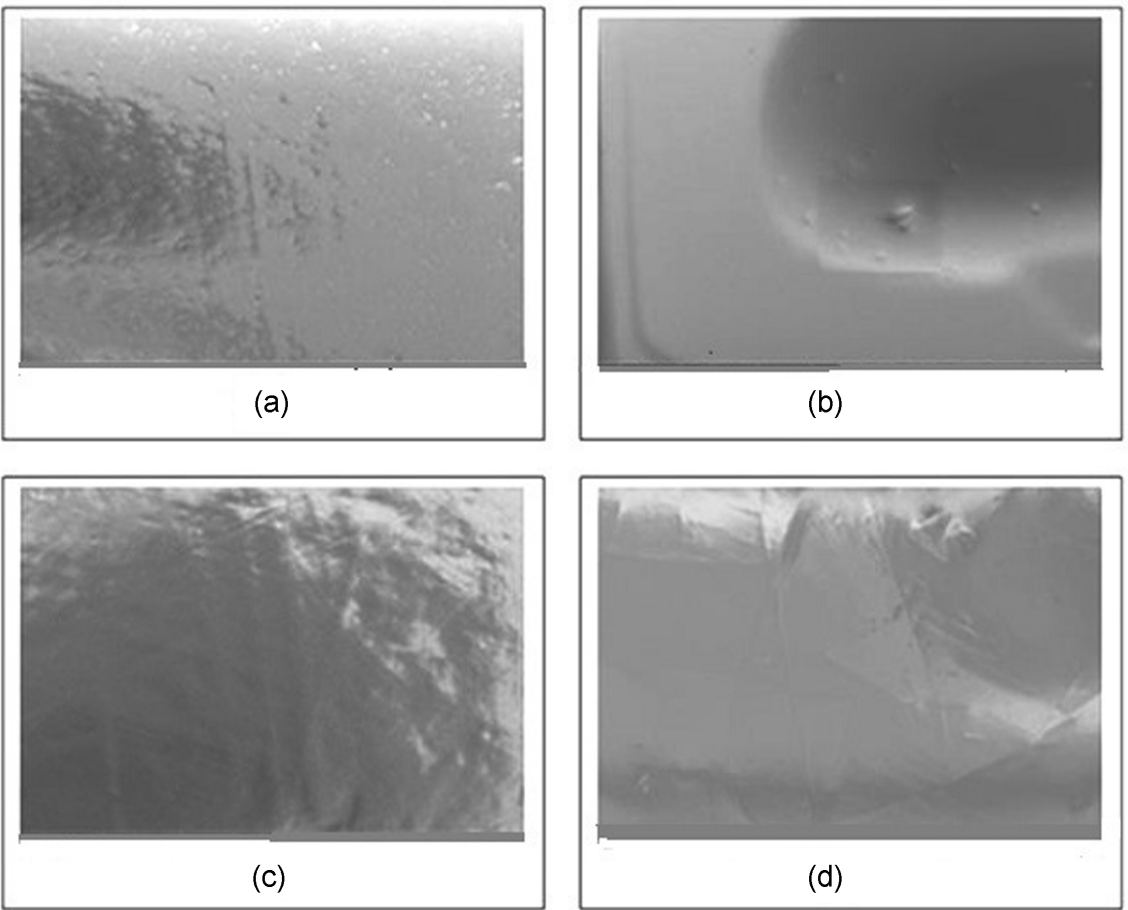

Figure 3. (a)-(d) SEM image of surface of CR-36 film treatment with DC discharge current equal to $5 \mathrm{~mA}$ and pressure at 1 torr: (a) untreated; (b) 1 min treatment; (c) $5 \mathrm{~min}$ treatment; and (d) 20 min treatment. 


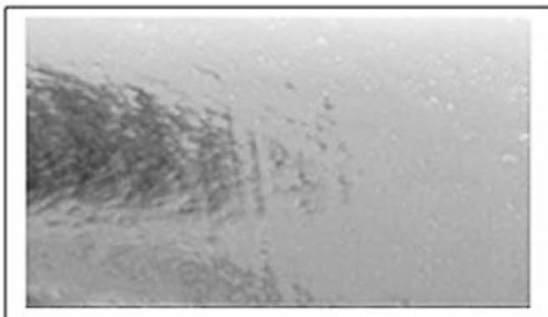

(a)

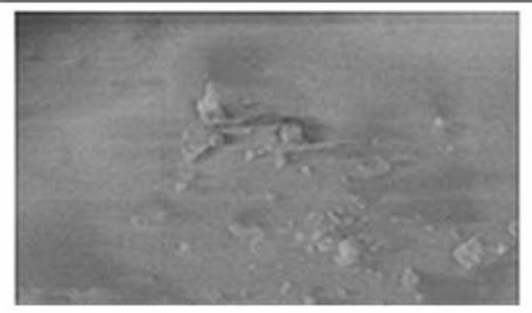

(c)

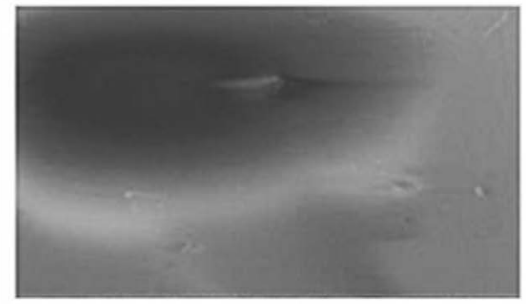

(b)

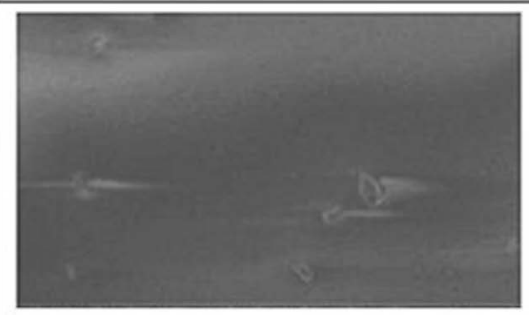

(d)

Figure 4. (a)-(d) SEM image of surface of CR-39 film treatment with RF discharge at $100 \mathrm{~W}$ power and pressure at 1 torr: (a) untreated; (b) 1 min treatment; (c) 5 min treatment; and (d) 20 min treatment.

insoluble in water thus suggesting that the film is a highly cross-linked network.

It can be seen that the surface roughness is increased after the treatment by RF and DC plasma. Compared with DC plasma treatment, the RF plasma treatment seems to be more uniform, which indirectly proves that the RF plasma is more homogeneous than the DC plasma.

\subsection{AFM Measurements}

AFM was employed to examine the surface morphology of the CR-39 surfaces and observe physical changes after the plasma treatment.

Figure 5 and Figure 6 show the surface morphology of the CR-39 polymer after plasma treatment using the two sources.

After DC plasma treatment, roughness of the CR-39 films is not considerably changed; only topographical modifications of polymer treated samples being observed (Figures 5(b)-(d)). On the other hand, polymer surfaces exposed to RF plasma present an increased roughness.

As seen in Figures 6(b)-(d), RF plasma treatment significantly alters the morphology of the CR-39 film; the pristine material has a smooth surface with no distinguishable features, while after RF plasma treatment, a number of depressions are created on the sample surface. This change in surface morphology is believed to result mainly from the bombardment of the surface by high energy ions present in the RF plasma. It indicates that, cross-linking phenomenon enhanced due to plasma treatment.

\subsection{IR Measurements}

Figures 7-9 show the IR spectra of untreated and plasma treated samples of the 


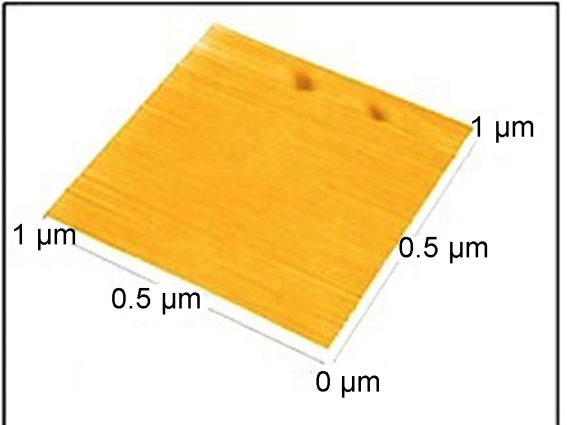

(a)

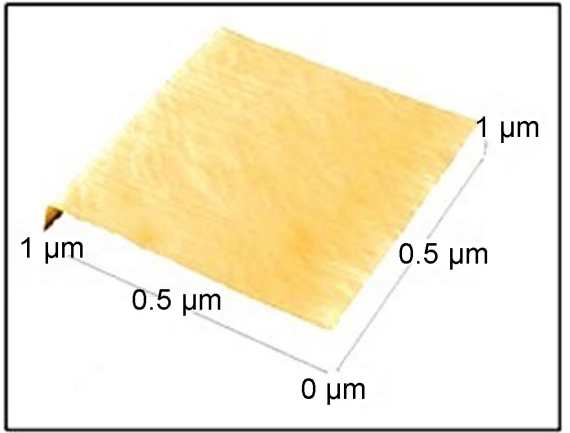

(c)

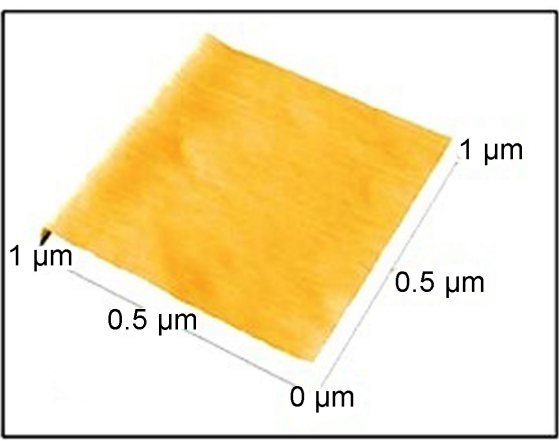

(b)

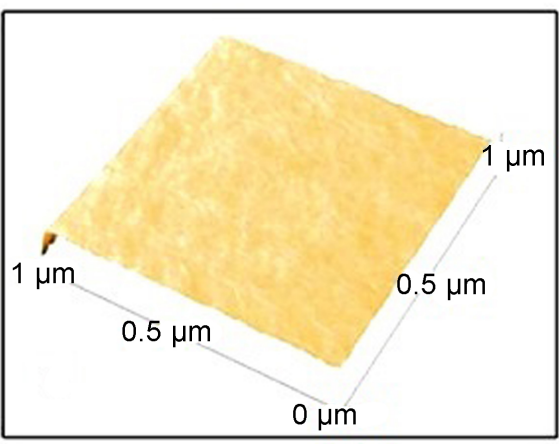

(d)

Figure 5. (a)-(d) AFM image of surface of CR-36 film treatment with DC discharge at current equal to $5 \mathrm{~mA}$ and pressure at 1 torr: (a) untreated; (b) 1 min treatment; (c) $5 \mathrm{~min}$ treatment; and (d) 20 min treatment.

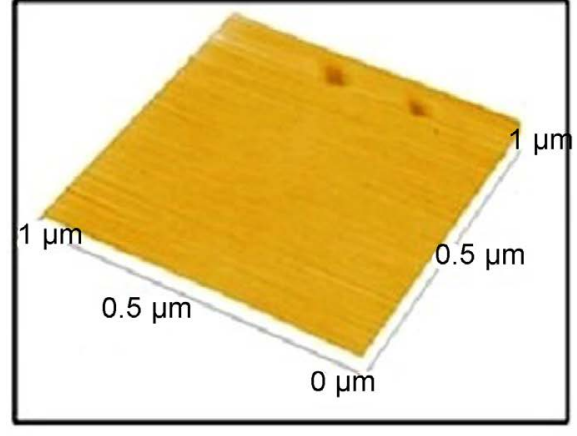

(a)

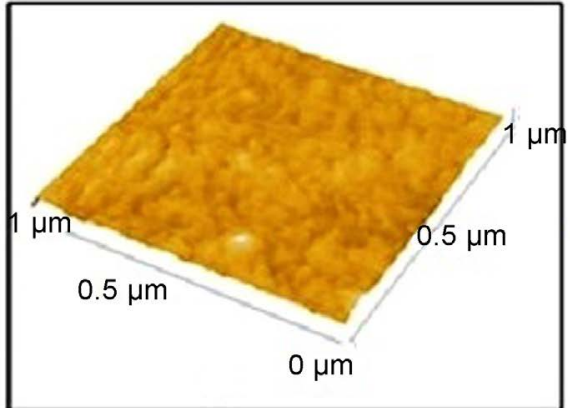

(c)

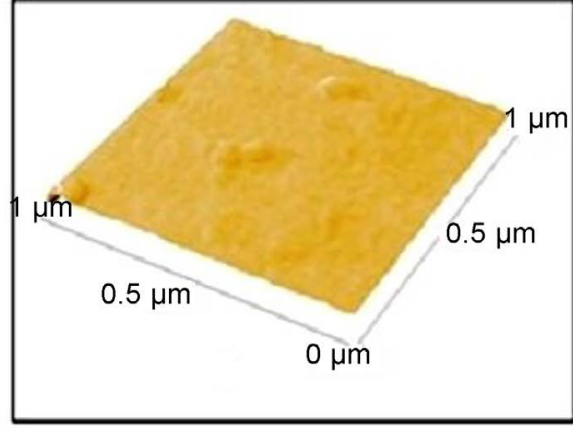

(b)

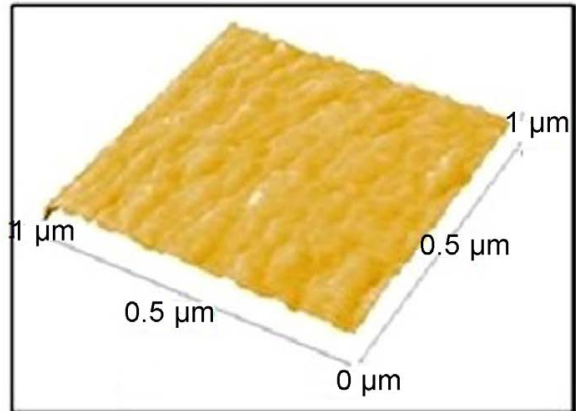

(d)

Figure 6. (a)-(d) AFM image of surface of CR-36 film treatment with RF discharge at 100 W power and pressure at 1 torr: (a) untreated; (b) 1 min treatment; (c) 5 min treatment; and (d) 20 min treatment. 


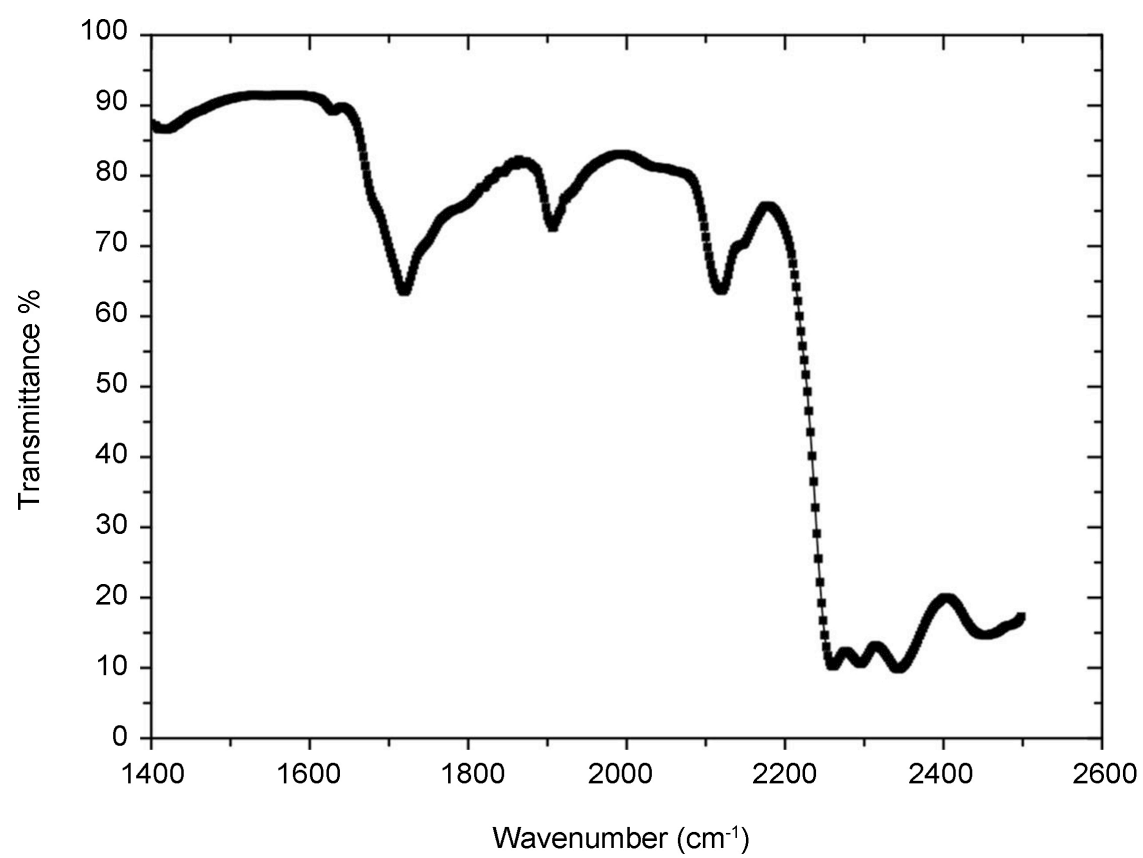

Figure 7. The IR spectra of the CR-39 film before plasma treatment.

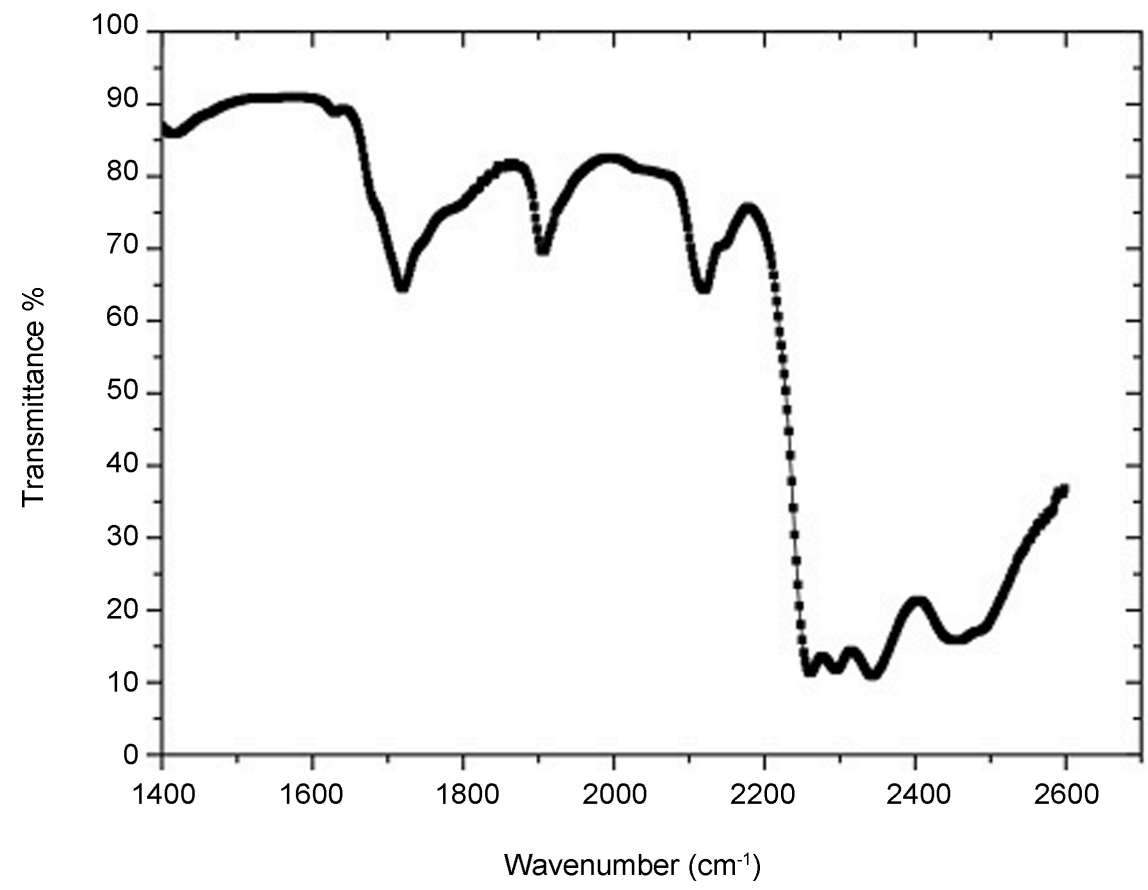

Figure 8. The IR spectra of CR-39 film after the plasma treatment with DC discharge current.

CR-39 polymer for both two plasma sources. In these spectra one can see the presence of different carbon-bearing bands. The peaks appearing at $1760.5 \mathrm{~cm}^{-1}$, $1970.4 \mathrm{~cm}^{-1}$ and $2165.7 \mathrm{~cm}^{-1}$ in IR spectra of CR-39 film indicates the presence of $\mathrm{CO}, \mathrm{CC}$ and $\mathrm{CH}$ double bonds, respectively. Thus, the IR spectral evidence clearly shows that we obtained the polymer film of CR-39 without much destruction 


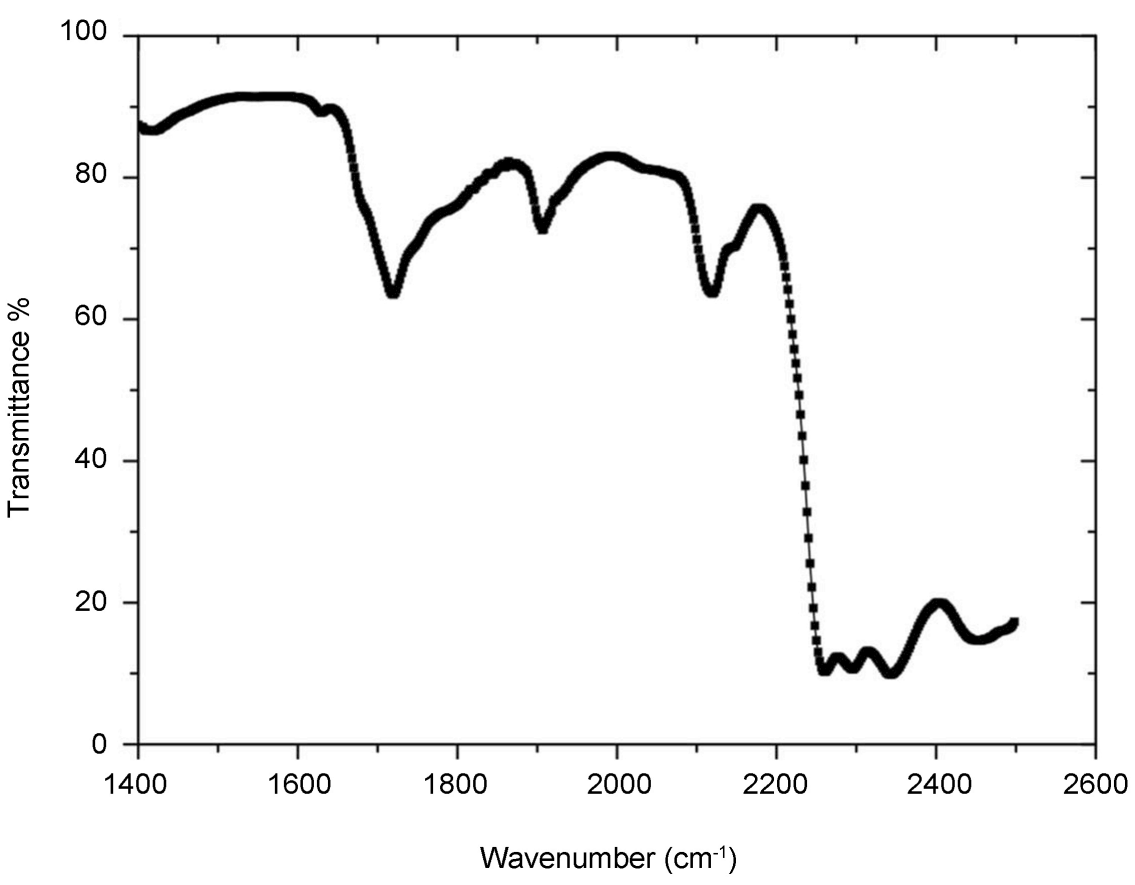

Figure 9. The IR spectra of CR-39 film after the plasma treatment with RF discharge current.

of its structure.

There is no growth of these peaks at different experimental conditions and/or plasma type is observed, indicates that the treatments are successful in forming a barrier layer to the diffusion of water vapor. This may be because the argon plasma modification produces an amorphous carbon layer below the surface, by promoting dense cross-linking of the polymer chains [24].

The appearance of additional peaks in the spectrum indicates the enhancement of radiation effects, which lead to the formation of more active chemical bonds increasing the degree of cross-linking [25]. The relative changes of the peaks (weakening, strengthening, broadening, and shifting) and the appearance of additional peaks observed in the exposed CR-39 suggest a significant change of the chemical structure of the polymer. Also, the increase of the peaks may be due to the presence of atmospheric oxygen as well as the double bond $(\mathrm{C}=\mathrm{O}$ bond), ( $\mathrm{C}=\mathrm{C}$ bond $)$.

\subsection{Refractive Index Measurements}

The refractive indices (n) (Table 1 ) were measured with a manual null-type research ellipsometer (Rudolph Research, USA). Typically, the refractive index could be determined to within \pm 0.04 .

It's clear that, the RF plasma enhanced the refractive indices of the CR-39 polymer than DC plasma.

We assume that, argon plasma modification is sufficient to capture hydrogen and to form free radicals at or near the surface which then interact mainly to produce a highly branched and chemically cross-linked structure. A cross-linking 
Table 1. The refractive index values for CR-39 films after the plasma treatment using the two plasma sources.

\begin{tabular}{ccc}
\hline Plasma treatment time $(\mathrm{min})$ & $\mathrm{n}$ (for RF plasma) & $\mathrm{n}$ (for DC plasma) \\
\hline 1 & 1.45 & 1.45 \\
5 & 1.47 & 1.46 \\
10 & 1.49 & 1.47 \\
15 & 1.52 & 1.49 \\
20 & 1.55 & 1.52 \\
\hline
\end{tabular}

reaction known as CASING (cross-linkage by activated species of inert gases), and unsaturated groups with chain scission or degradation located in a thin surface layer [26].

\section{Conclusions}

Surface modification of polymer by plasma is the most effective way of uniform and controlled treatment.

Surface treatment of CR-39 polymer has been carried out using two plasma sources, namely RF plasma at $13.56 \mathrm{MHz}$ and DC plasma.

The modified surface was characterized by contact angle measurements, scanning electron microscopy (SEM), atomic force microscopy (AFM), infra red (IR) spectroscopy and refractive index measurements. The modified surface, believed to be extensively cross-linked, however showed all the chemical characteristics of CR-39.

The results show that the wettability of the CR-39 polymer film has been improved due to the introduction of oxygen-containing polar groups and an increase in surface roughness.

It is found that, under the same conditions, the RF plasma is more effective for surface modification than DC plasma as the former can modify the surface more uniformly; implant more oxygen atoms into the surface and make the contact angle decline to a lower level. The differences in surface transformation between RF and DC glow discharges are related also to their discharge properties because more active species can interact with the surface in the case of RF plasmas treatment.

It is found that the change in surface properties depends on the plasma treatment time. The higher the treatment time is accompanied by the better of the surface treatment of the polymer.

Therefore, one can concluded that, the system described in this paper provides an efficient and non-destructive means of altering the surface properties of polymer surfaces.

\section{References}

[1] Ahn, K.H., Park, Y.B. and Park, D.W. (2003) Surface and Coatings Technology, 171, 198-204. 
[2] Babelon, P., Dequiedt, A.S., Mostéfa-Sba, H., Bourgeois, S., Sibillot, P. and Sacilotti, M. (1998) Thin Solid Films, 322, 63-67. https://doi.org/10.1016/S0040-6090(97)00958-9

[3] Clement, F., Held, B., Soulem, N. and Guimon, C. (2002) The European Physical Journal Applied Physics, 18, 135-151. https://doi.org/10.1051/epjap:2002035

[4] Singh, S. and Prasher, S. (2004) Nuclear Instruments and Methods in Physics Research Section B, 215, 169-173. https://doi.org/10.1016/S0168-583X(03)01815-9

[5] Kasalkova, N., Slepicka, P., Kolska, Z. and Svorcik, V. (2015) Wetting and Wettability. In: Aliofkhazraei, M., Ed., InTech.

https://www.intechopen.com/books/wetting-and-wettability/wettability-and-othersurface-properties-of-modified-polymers

[6] Yasuda, H.K. (1990) Plasma Polymerization and Plasma Interactions with Polymeric Materials. John Wiley and Sons, New York.

[7] Grill, A. (1993) Cold Plasma in Material Fabrications. The Institute of Electrical and Electronics Engineers, New York.

[8] Mandolfno, C., Lertora, E., Gambaro, C. and Bruno, M. (2014) Meccanica, 49, 2299-2306. https://doi.org/10.1007/s11012-014-9993-y

[9] Roth, J.R. (2001) Industrial Plasma Engineering, Volume 2: Applications to Non-thermal Plasma Processing. Institute of Physics Publishing, London.

[10] Samson, F. (1996) Surface and Coatings Technology, 81, 79-86. https://doi.org/10.1016/0257-8972(95)02532-4

[11] Srivatsa, K.K.M., Bera, M., Basu, A. and Bhattacharya, T.K. (2008) Bulletin of Materials Science, 31, 673. https://doi.org/10.1007/s12034-008-0107-0

[12] Kumar, D.S., Fujioka, M., Asano, K., Shoji, A., Jayakrishnan, A. and Yoshida, Y. (2007) Journal of Materials Science: Materials in Medicine, 18, 1831. https://doi.org/10.1007/s10856-007-3033-6

[13] Chan, C.-M., Ko, T.-M. and Hiraoka, H. (1996) Surface Science Reports, 24, 1-54. https://doi.org/10.1016/0167-5729(96)80003-3

[14] Arefi, K., Placinta, G., Amouroux, J. and Popa, G. (1998) The European Physical Journal, 4, 1.

[15] Massines, F. and Gouda, G. (1998) Journal of Physics D: Applied Physics, 31, 3411. https://doi.org/10.1088/0022-3727/31/24/003

[16] Ranby, B. and Rabek, J.F. (1975) Photo Degradation, Photo Oxidation and Photo Stabilization of Polymers, Principles and Applications. John Wiley, New York.

[17] Clement, F., Held, B., Soulem, N. and Martinez, H. (2003) The European Physical Journal, 21, 59.

[18] Martinu, L. and Poitras, D. (2000) Journal of Vacuum Science \& Technology A, 18, 2619.

[19] Keil, M., Rastomjee, C.S., Rajagopal, A., Sotobayashi, H., Bradshaw, A.M., Lamont, C.L.A., Gador, D., Buchberger, C., Fink, R. and Umbach, E. (1998) Applied Surface Science, 125, 273. https://doi.org/10.1016/S0169-4332(97)00501-1

[20] Morent, R., Geyter, N., Gengembre, L., Leys, C., Payen, E., Vlierberghe, S. and Schacht, E. (2008) The European Physical Journal Applied Physics, 43, 289. https://doi.org/10.1051/epjap:2008076

[21] Panwar, A.K., Barthwal, S.K., Shivaprasad, S.M. and Ray, S. (2008) Journal of Physics D: Applied Physics, 41, Article ID: 135305. 
https://doi.org/10.1088/0022-3727/41/13/135305

[22] Hassouba, M.A., ASaad, M.A. and Elakshar, F.F. (2004) Fizika, B1, 105.

[23] Pandiyaraj, K.N., Selvarajan, V., Deshmukh, R.R. and Bousmina, M. (2008) Surface Coatings Technology, 202, 4218. https://doi.org/10.1016/j.surfcoat.2008.03.015

[24] Rafique, M.S., Bashir, S., Ajami, A., Husinsky, W., Hobro, A. and Lendl (2010) Applied Physics $A, 101,551$. https://doi.org/10.1007/s00339-010-5896-5

[25] Bilek, M.M., Newton, K., Mc-Kenzie, D.R. and Mc-Culloch, D.G. (2006) Nuclear Instruments and Methods in Physics Research Section B, 242, 221.

[26] Agostino, R., Favia, P., Kawai, Y., Ikegami, H., Sato, N. and Arefi, K. (2008) Advanced Plasma Technology. John Wiley \& Sons. 